\title{
A new method to isolate americium from environmental samples using Diphonix resins
}

\author{
C. Gasco, M.P. Anton, N. Navarro ${ }^{1}$ and A.M. Gonzalez \\ Centro de Investigaciones Energéticas, Medioambientales y Tecnologicas, CIEMAT, \\ Departamento de Impacto Ambiental de la Energia, DIAE, \\ Avenida Complutense 22, 28040 Madrid, Spain \\ ${ }^{1}$ Centro de Investigaciones Energéticas, Medioambientales y Tecnologicas, CIEMAT, \\ Secretaria General de Relaciones Externas e Institucionales, SEGREI, \\ Avenida Complutense 22, 28040 Madrid, Spain
}

\begin{abstract}
The Aquatic Radioactivity Laboratory of Ciemat has been performing transuranic analyses in different types of matrices such as soils, marine sediments and biota for a good number of years. Analysing americium in large size/volume samples by employing ionic-exchange resins becomes a long and tedious process, usually resulting in low chemical recoveries. A new procedure to isolate americium from environmental samples has been developed by concentrating americium in a Diphonix resin. This resin is then destroyed by calcination at $550^{\circ} \mathrm{C}$ and further digestion with $\mathrm{HNO}_{3}$ and $\mathrm{H}_{2} \mathrm{O}_{2}$ in a microwave oven programmed with increasing pressure stages, reaching 175 psi. Isolation is completed with TRU.Spec and TEVA.Spec columns. Americum is finally quantified by high resolution alpha spectrometry. Analyses carried out with various reference IAEA materials proved that this new method produces higher radiochemical yields, thus allowing treatment of smaller environmental samples.
\end{abstract}

\section{INTRODUCTION}

The analytical methods employed to measure radionuclide concentrations in aquatic ecosystems vary depending on the nature of the sample (water, particulate matter, sediments, biota), the number and abundance of chemical and radiochemical interferents (metals, lanthanides, natural radionuclides), the sample size, etc. The determination of very low activities of long-lived radionuclides, especifically alphaemitters, implies the development and implementation of a complex analytical methodology. First, the selected radionuclide must be concentrated to a measurable quantity and then, it must be isolated from the different interferents present in the sample to finally obtain a homogeneous microdeposit suitable to be quantified by alpha spectrometry.

The Aquatic Radioactivity Laboratory of Ciemat has been performing transuranic analyses in diverse matrices for a number of years. In general terms, the most common radiochemical methodology involves the following steps: a) quantitative extraction of transuranics by acid digestion either with a mixture of strong acids, such as $\mathrm{HNO}_{3}, \mathrm{HCl}$ and $\mathrm{FH}$ when refractories compounds are suspected to be present in the sample or with $\mathrm{HNO}_{3} 8 \mathrm{~N}$ when dealing with fallout radionuclides, b) concentration of the selected radionuclides by co-precipitation with calcium oxalates and iron hidroxides to eliminate most of the interferents remaining in the supernatant to be discarded and c) radiochemical isolation by separation with ionic resins and/or cromatographic extraction. When analysing americium in large size samples the latter stage becomes long and tedious when employing anionic/cationic resins, usually resulting in low chemical recoveries. For this reason cromatographic extraction resins Tru-Spec and Teva-Spec are routinely used at present in our lab.

Moreover, to improve the global chemical yield of the method, thus allowing the processing of smaller sample sizes, the concentration phases through co-precitation have been eliminated by employing Diphonix resins to retain the americium. This resin contains geminally-substituted diphosphonic acid groups chemically bonded to a styrene-divinylbenzene copolymer, exhibiting a high affinity for actinides in the tri, tetra and hexavalent oxidation states [1]. Diphonix resin is then destroyed by digestion with $\mathrm{HNO}_{3}$ and $\mathrm{H}_{2} \mathrm{O}_{2}$ in a microwave oven programmed with increasing pressure stages. Finally, americium is electroplated onto stainless steel discs that are then quantified by high resolution alpha spectrometry. 


\section{METHODOLOGY}

To check the validity of the method employed, five gram aliquots of IAEA327 and IAEA300 reference materials have been analysed following the procedure displayed in Figure 1.

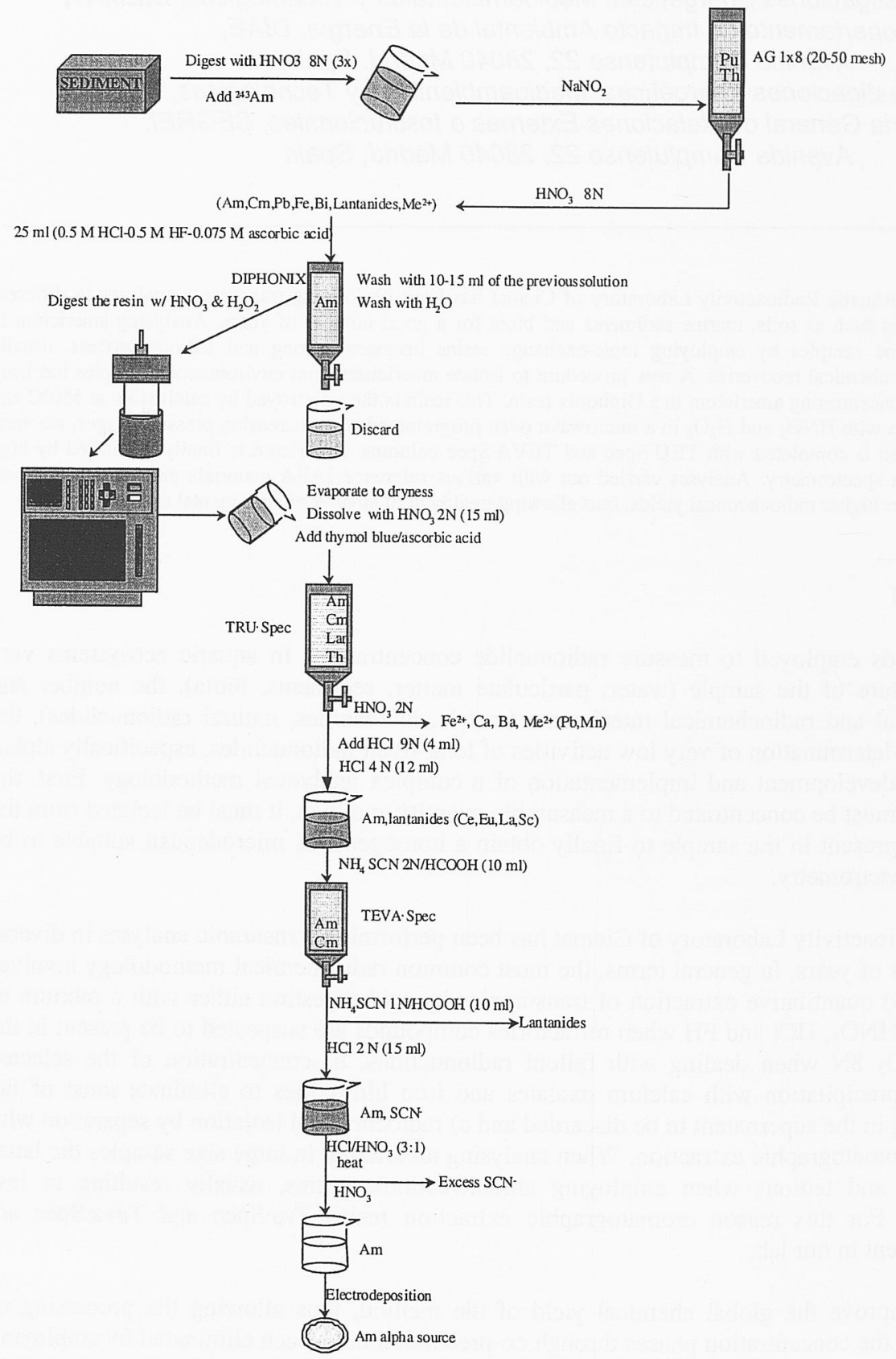

Figure 1: Scheme of the analytical procedure employed to isolate americium using Diphonix resin. 
The analysed samples have been referenced as: Am-no interferences, IAEA-327 gamma and IAEA-327 apha.

Am-no interferences served to test the americium retention capacity of the Diphonix resin with no marrix interferences. This sample was spiked with a known activity of ${ }^{241} \mathrm{Am}(135.8 \pm 0.5 \mathrm{~Bq})$ provided by the Metrology Laboratory from Ciemat. Elution aliquots of $5 \mathrm{~mL}$ each were collected from the columns (Diphonix, Tru-Spec and Teva.Spec) after loading the different reagents (see Figure 1). Am-241 was traced through the whole process by measuring it by gamma spectrometry.

IAEA-327 gamma served to test the americium retention capacity of the Diphonix resin when analysing a soil with chemical interferents (metals and rare earths). This sample was spiked with a known activity of ${ }^{241} \mathrm{Am}(135.8 \pm 0.5 \mathrm{~Bq})$ provided by the Metrology Laboratory from Ciemat. Elution aliquots of $5 \mathrm{~mL}$ each were collected from the columns after loading the different reagents (see Figure 1). Am-241 was tracked down by measuring it by gamma spectrometry.

IAEA-327 alpha served to test the metals and rare earths retention capacity of the Diphonix resin when analysing a soil with chemical interferents. This sample was spiked with a known activity of an internal tracer, ${ }^{243} \mathrm{Am}$, used to calculate the chemical yield. Elution aliquots of $5 \mathrm{~mL}$ each were collected from the columns after loading the different reagents (see Figure 1). Chemical interferents were traced through the various method steps by measuring them by ICP-AES (metals) and ICP-MS (rare earths). Americium was quantified by alpha spectrometry.

Two aliquots of sample IAEA-300 were also analysed with the procedure routinely employed in the americium determinations by alpha spectrometry when using Diphonix resins.

\section{RESULTS AND DISCUSSION}

The analysis of the sample just containing an added activity of ${ }^{241} \mathrm{Am}$ (Am-241 no interferences) produced a final activity quantified by gamma spectrometry of $110.7 \pm 8.0 \mathrm{~Bq}$. The maximum americium activity measured in the $5 \mathrm{~mL}$ aliquots eluted from the Diphonix column was $5.8 \mathrm{~Bq}$, therefore, a retention percentage of $\sim 96 \%$ is obtained for this radionuclide when no interferences are present in the sample. Continuing with the analysis, the $5 \mathrm{~mL}$ aliquots collected from Tru $S$ Spec and Teva.Spec columns contained a maximum activity of $8.7 \mathrm{~Bq}$ all together. Thus, the final chemical recovery achieved for americium was $82 \pm 6 \%$. The Am-241 losses are attributed to the manipulation of the sample.

The analysis of the sample IAEA-327 gamma resulted in a final ${ }^{241}$ Am activity quantified by gamma spectrometry of $86.1 \pm 6.4 \mathrm{~Bq}$. A retention percentage of $\sim 96 \%$ has been calculated for americium in the Diphonix resin when matrix interferents (aluminum, iron, calcium, magnesium, manganese, and lasthanides such as cerium, lanthane and neodimiun) were present in the soil sample. The maximun americium activity quantified in the $5 \mathrm{~mL}$ aliquots drained from the above mentioned column was $4.7 \mathrm{~Bq}$. The eluates obtained from Tru.Spec and Teva.Spec resins amounted for $8.1 \mathrm{~Bq}$. Therefore, the Am chemical recovery calculated was $63 \pm 5 \%$. The presence of matrix interferences as well as the long manipulation of the sample would be responsible for the americium losses through the whole processing.

The analysis of sample IAEA-327 alpha resulted in a final chemical recovery for ${ }^{241} \mathrm{Am}$ of $63 \pm 2 \%$. The metals and rare earths analyses performed in the $5 \mathrm{~mL}$ aliquots collected from the Diphonix resin provided useful information about the retention capacity of this resin to either eliminate or adsorb the main matrix interferents, as it can be seen in Table 1. It should be noticed that metals are rarely retained by the resin, while rare earths appear to be adsorbed in large percentages. Cromatographic resins hold different elements based on their size (ionic ratio) and capacity to form stable complexes with the organic ligands conforming the resin. In the case of aluminum a higher quantity is obtained, due to the storage of the aliquots in glass beakers before their analytical determination. 
Table 1. Retention capacity of Diphonix resin

\begin{tabular}{|c|c|c|c|c|c|c|c|c|}
\hline Element & $\mathrm{Al}$ & $\mathrm{Fe}$ & $\mathrm{Ca}$ & $\mathrm{Mg}$ & $\mathrm{Mn}$ & $\mathrm{Ce}$ & $\mathrm{La}$ & $\mathrm{Nd}$ \\
\hline $\begin{array}{c}\text { Input } \\
\text { (mg) }\end{array}$ & 41 & 70 & 3.7 & 8.9 & 5 & 0.13 & 0.05 & 0.07 \\
\hline $\begin{array}{c}\text { Output } \\
\text { (mg) }\end{array}$ & 51 & 69 & 4.4 & 8 & 4.9 & 0.03 & 0.008 & 0.01 \\
\hline $\begin{array}{c}\text { Retention } \\
\%\end{array}$ & 0 & 2 & 0 & 10 & 2 & 81 & 84 & 87 \\
\hline
\end{tabular}

The americium retention capacity as well as the decontamination factors of resins Tru.Spec and Teva-Spec have been previously investigated and published in the literature [2,3]. In this particular case, since Diphonix resin is completely destroyed in the microwave, it can be assumed that the amount of metals and rare earths retained will be loaded onto the Tru-Spec column. The results obtânned are summarized in Table 2.

Table 2. Retention capacity of Tru-Spec resin (up until elution of Am)

\begin{tabular}{|c|c|c|c|c|c|c|c|c|}
\hline Element & $\mathrm{Al}$ & $\mathrm{Fe}$ & $\mathrm{Ca}$ & $\mathrm{Mg}$ & $\mathrm{Mn}$ & $\mathrm{Ce}$ & $\mathrm{La}$ & $\mathrm{Nd}$ \\
\hline $\begin{array}{c}\text { Input } \\
\text { (mg) }\end{array}$ & 0 & 1 & 0 & 0.9 & 0.11 & 0.103 & 0.04 & 0.061 \\
\hline $\begin{array}{c}\text { Output } \\
\text { (mg) }\end{array}$ & --- & 6.4 & -- & 0.1 & 0.1 & 0.00003 & 0.005 & 0.00001 \\
\hline $\begin{array}{c}\text { Retention } \\
\%\end{array}$ & --- & --- & -- & 90 & 5 & 100 & 87 & 100 \\
\hline
\end{tabular}

Tru-Spec resin has proven in earlier studies a strong capacity to eliminate metal tracers and natural radionuclides (uranium, thorium), which are retained by the resin in very high percentages[2]. Rare earths are retained, along with americium up until their elution from the column with $\mathrm{HCl} 4 \mathrm{~N}$. Considering that the elution obtained from the Tru-Spec is quantitative, it can be infered the amount of interferents to be passed through Teva-resin, thus allowing the retention percentages for this resin to be estimated, as shown in Table 3.

Table 3. Retention capacity of Teva.Spec resin (up until the elution of Am)

\begin{tabular}{|c|c|c|c|c|c|c|c|c|}
\hline Element & $\mathrm{Al}$ & $\mathrm{Fe}$ & $\mathrm{Ca}$ & $\mathrm{Mg}$ & $\mathrm{Mn}$ & $\mathrm{Ce}$ & $\mathrm{La}$ & $\mathrm{Nd}$ \\
\hline $\begin{array}{l}\text { Input } \\
\text { (mg) }\end{array}$ & --- & & --- & --- & --- & 0.103 & 0.036 & 0.061 \\
\hline $\begin{array}{l}\text { Output } \\
\text { (mg) }\end{array}$ & -- & -- & --- & --- & --- & 0.13 & 0.04 & 0.08 \\
\hline $\begin{array}{c}\text { Retention } \\
\%\end{array}$ & --_- & --- & --- & --- & --- & 0 & 0 & 0 \\
\hline
\end{tabular}

These data show that rare earths are completely drained from the resin prior to americium elution, therefore ensuring the isolation of this radionuclide for its further electrodeposition and alpha-counting. For a better understanding of the metals and rare earths evolution through out all the three resins employed, Figure 2 displays the interferents graphs.

Two aliquots of IAEA 300 were also analysed. The chemical recoveries obtained were $93 \pm 4 \%$ and $98 \pm 4 \%$. These values are incredibly high, pointing to a mishandling of the tracers used or an incorrect manipulation during the chemical procedure. Therefore, a further study about the reproducibility of the methos is seriously needed. 

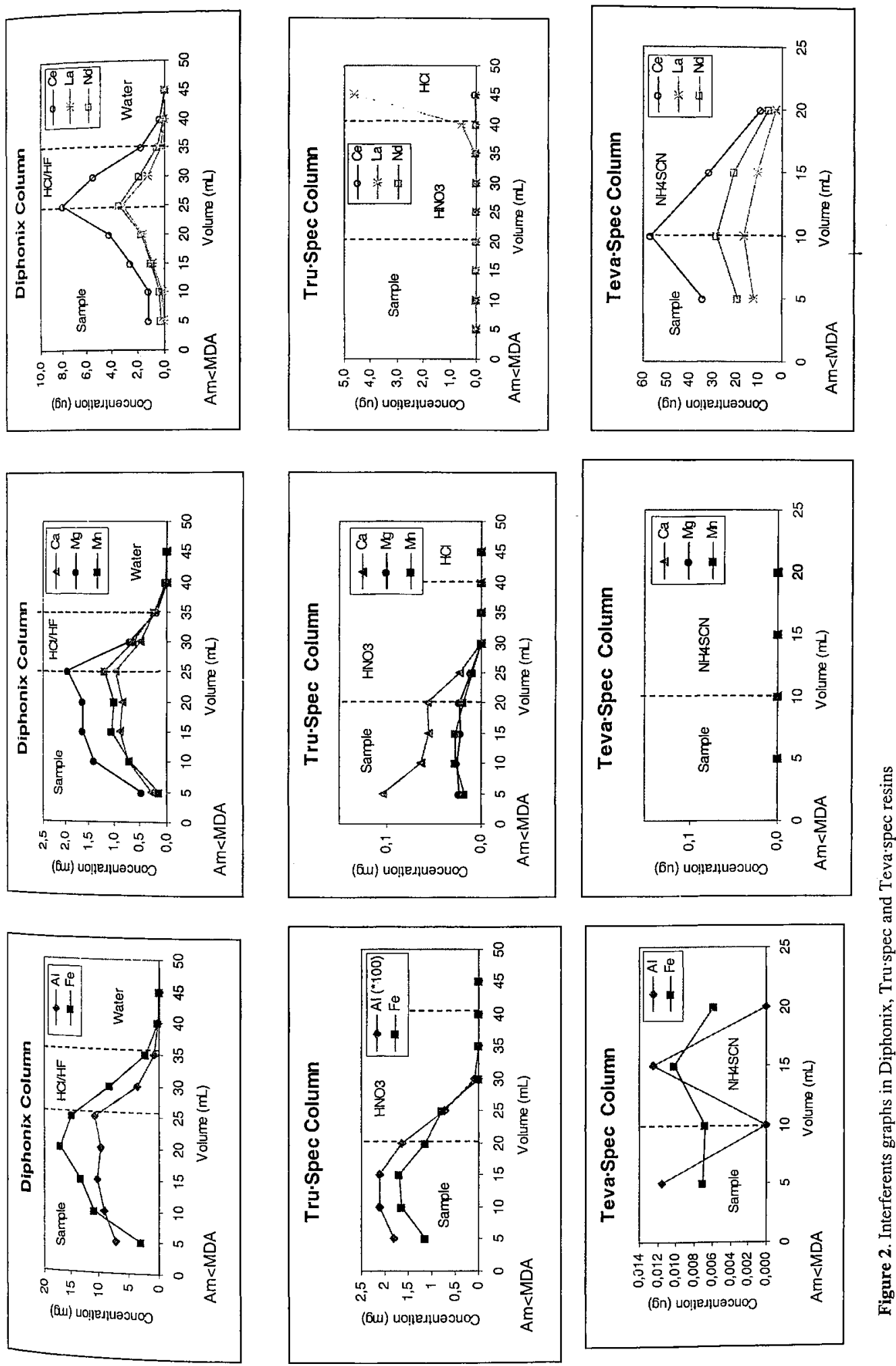


\section{CONCLUSIONS}

Diphonix resin retains the americium in $>90 \%$ when chemical interferents are present in the sample. Major soil components such as iron, aluminium and calcium are not, passing through the resin. Rare earths are held in $>85 \%$, however, they are efficiently eliminated by the TEVA.Spec resin before the Am is eluted.

Americium chemical recovery in a sample containing chemical interferents is $20 \%$ lower than that obtain when analysing a blank with no interferences. This loss is caused more by the higher number of stages involved in the methodology than the interferents themselves, since they are effectively eliminated without interfering in the Am elution.

Further tests are necessary to check the reproducibility of the method employed.

\section{Acknowledgements}

The authors are grateful to Drs. A. Quejido and M. Fernandez (Chemistry lab. Ciemat) for performing the metals and rare earths analyses. We are also grateful to Dr. M Crespo (Metrology Dpt., Ciemat) for providing Am241 solution.

\section{References}

[1] S.L. Maxwell III, S.T. Nichols "Actinide-Recovery Method for Large-Soil Samples".

[2] C. Gasco, M.P. Anton, A. Alvarez, N. Navarro, S. Salvador (1994). « Método analitico para la determinacion de Am241 en muestras biolçogicas y sedimentos marinos, ediante uso de una columna con extractante organico ». CIEMAT Report 745, ISSN 0214-087X.

[3] C. Gasco, M.P. Anton, A. Espinosa, A. Aragon, A. Alvarez, N. Navarro, E. Garcia-Torano (1997). "Procedures to define isotopic ratios characterizing a contaminated area in Palomares “Spain)". J. Radio. Nucl. Chem., Vol 222, N. 1-2,81-86. 